\title{
Correction to: Removal of aqueous carbamazepine using graphene oxide nanoplatelets: process modelling and optimization
}

Sandipan Bhattacharya ${ }^{1}$, Priya Banerjee ${ }^{2}$, Papita Das ${ }^{1,3^{*}}$, Avijit Bhowal $^{1,3}$, Subrata Kumar Majumder ${ }^{4}$ and Pallab Ghosh ${ }^{4}$

Correction to: Sustain Environ Res 30, 17 (2020) https://doi.org/10.1186/s42834-020-00062-8

Following publication of the original article [1], the authors identified an error in the names of an author.

The incorrect name was: Subrata K. Majumdar

The correct author name is: Subrata Kumar Majumder

The author group has been updated above and the original article [1] has been corrected.

\begin{abstract}
Author details
'Department of Chemical Engineering, Jadavpur University, Kolkata 700032, India. ${ }^{2}$ Department of Environmental Studies, Rabindra Bharati University, Kolkata 700091, India. ${ }^{3}$ School of Advanced Studies in Industrial Pollution Control Engineering, Jadavpur University, Kolkata 700032, India. ${ }^{4}$ Department of Chemical Engineering, Indian Institute of Technology Guwahati, Guwahati 781039, India.
\end{abstract}

Published online: 07 October 2020

\section{Reference}

1. Bhattacharya, S., Banerjee, P., Das, P. et al. Removal of aqueous

carbamazepine using graphene oxide nanoplatelets: process modelling and optimization. Sustain Environ Res 30, 17 (2020). https://doi.org/10.1186/ s42834-020-00062-8

\footnotetext{
The original article can be found online at https://doi.org/10.1186/s42834020-00062-8.

* Correspondence: papitasaha@gmail.com

${ }^{1}$ Department of Chemical Engineering, Jadavpur University, Kolkata 700032,

India

${ }^{3}$ School of Advanced Studies in Industrial Pollution Control Engineering,

Jadavpur University, Kolkata 700032, India

Full list of author information is available at the end of the article
}

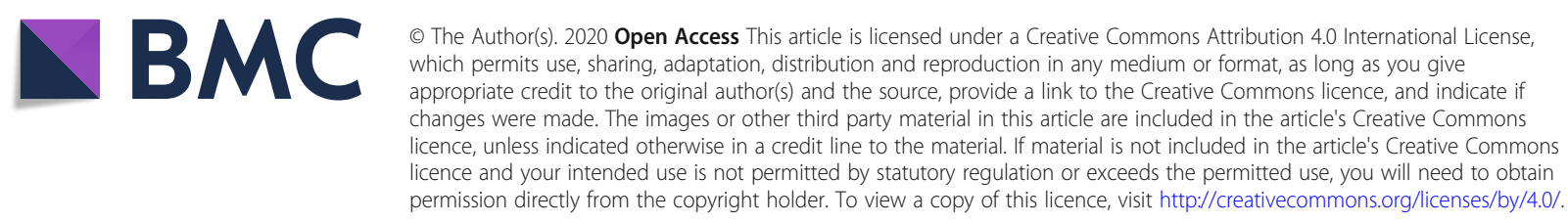

